\title{
Vaginal Dilator
}

National Cancer Institute

\section{Source}

National Cancer Institute. Vaginal Dilator. NCI Thesaurus. Code C157720.

A device designed to enlarge the vaginal canal in depth or diameter. 